archives

of thermodynamics

Vol. 37(2016), No. 2, 41-69

DOI: $10.1515 /$ aoter-2016-0012

\title{
The analysis of thermal and flow characteristics of the condensation of refrigerant zeotropic mixtures in minichannels
}

\author{
TADEUSZ BOHDAL* \\ KATARZYNA WIDOMSKA \\ MAEGORZATA SIKORA
}

Technical University of Koszalin, Department of Heat and Refigeration

Engineering, Racławicka 15-17, 75-620 Koszalin, Poland

\begin{abstract}
The paper presents the results of experimental heat transfer and pressure drop during condensation of the single component refrigerant R134a and zeotropic mixtures R404A, R407C, and R410A in tube minichannels of internal diameter from the range $0.31-3.30 \mathrm{~mm}$. The local values and the average of heat transfer coefficient and pressure drop in the whole range of the change in mass quality were measured. On the basis of the obtained test results there was illustrated the influence of the change of mass vapor quality, the mass flux density, and the inner diameter of channel on the studied parameters. These results were compared with the calculation results based on the relations postulated by other authors. The discrepancy range was $\pm 50 \%$. On the basis of given test results own correlation was developed to calculate the heat transfer coefficient and pressure drop of tested refrigerants which presents the obtained results in a range of discrepancy of $\pm 25 \%$.
\end{abstract}

Keywords: Minichannels; Condensation; Zeotropic mixture; Heat transfer coefficient; Pressure drop

\section{Nomenclature}

$$
\begin{array}{lll}
d & - & \text { minichannel inner diameter, } \mathrm{m} \\
f & - & \text { friction coefficient } \\
G & - & \text { mass flux density, } \mathrm{kg} /\left(\mathrm{m}^{2} \mathrm{~s}\right)
\end{array}
$$

\footnotetext{
${ }^{*}$ Corresponding Author. E-mail: Tadeusz.Bohdal@tu.koszalin.pl
} 


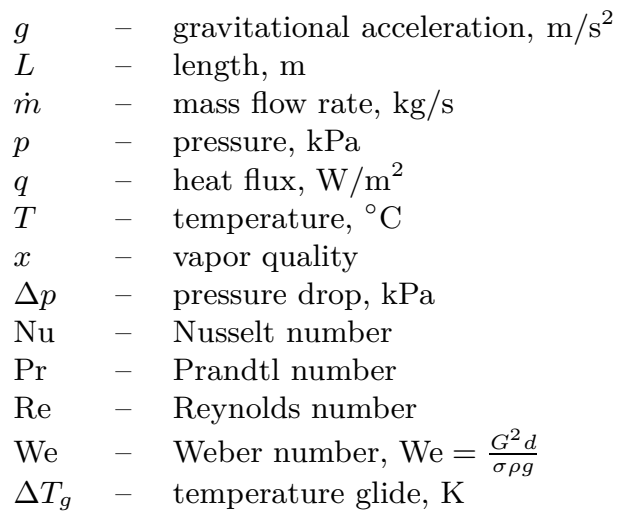

\section{Greek symbols}

$\alpha-$ heat transfer coefficient, $\mathrm{W} /\left(\mathrm{m}^{2} \mathrm{~K}\right)$

$\lambda-$ thermal conductivity coefficient, $\mathrm{W} /(\mathrm{m} \mathrm{K})$

$\mu \quad-$ dynamic viscosity, $\mathrm{kg} /(\mathrm{ms})$

$\rho \quad-$ density, $\mathrm{kg} / \mathrm{m}^{3}$

$\sigma \quad-$ surface tension, $\mathrm{N} / \mathrm{m}$

\section{Subscripts}

$\begin{array}{lll}a & - & \text { averaging conditions } \\ c r & - & \text { critical value } \\ e x p & - & \text { experimental values } \\ f & - & \text { llow of one phases } \\ g & - & \text { gas } \\ g o & - & \text { gas only } \\ H & - & \text { hydrostatic } \\ i & - & \text { flowing section } \\ l & - & \text { liquid } \\ l o & - & \text { liquid only } \\ r & - & \text { reduced pressure } \\ s & - & \text { saturation value } \\ t h & - & \text { theoretical value } \\ T P & - & \text { two phase } \\ T P F & - & \text { two phase frictional } \\ x & - & \text { local value }\end{array}$

\section{Introduction}

Due to the destructive impact of refrigerants from chlorofluorocarbons (CFC) and hydrochlorofluorocarbons HCFC) groups on the natural environment, in particular on the destruction of the ozone layer and the intensification of global warming, radical actions were taken in order to eliminate derived chlorinated substances from a common use. The first international 
agreement which was aimed at protecting the environment was the 'Montreal Protocol' [22] implemented on 16 Sept. 1987. The consequence of it is the 'Act on substances that deplete the ozone layer' [30] from 20 April 2004 passed by the Council of the European Union and ratified by the Polish Parliament. These documents regulate the use and operation rules of substances harmful to the ozone layer, as well as prohibit the widespread use of refrigerants of CFCs (R11, R12) and HCFC (since 01 Jan. 2010 freon R22 has been completely removed from the newly designed refrigeration plants). These restrictions affected the increased search of substitutes, withdrawn CFCs. The substitutes of these freons should meet a number of criteria, including: the relevant chemical, physical and thermodynamic criteria and also further criteria concerning environmental performance, economy and security.

Removed refrigerants are successively controlled and replaced with ecological refrigerants having similar physicochemical properties, including agents of natural origin and synthetic origin, mainly homogeneous agents and their mixtures. For example, as a replacement of R22 there are usually proposed such zeotropic mixtures as R404A, R407C, and R410A [5].

In recent years R134a has been the most popular substitute for R12. Despite its obvious thermodynamic advantages, this refrigerant has a very high global warming potential $\left(\mathrm{GWP}_{R 134 a}=1430\right)[7]$. This fact affected the decision about its withdrawal. According to the Directive of the European Parliament and the Council of Europe No. 2006/40/EC the use of fluorinated greenhouse gases for which GWP value is greater than 150 is limited in all newly manufactured refrigeration and MAC (mobile air conditioning) systems. It was suggested that since 1 Jan. 2011, R134a should be withdrawn from vehicle air conditioning systems in all new models and next since 1 Jan. 2017 the use of R134a will be prohibited in all newly manufactured vehicles $[1,27,31]$. Ultimately, this refrigerant is to be replaced with a new, environment - friendly refrigerant from hydrofluoroolefin (HFO-1234yf) group [1,31].

Accordingly, zeotropic mixture (ZEO) and nearly azeotropic refrigerant mixtures (NEARM or MBA) are becoming more and more popular in refrigeration. These are the refrigerants, which are a mixture of two or more one-component refrigerants with a determined percentage mass concentration in the mixture. The characteristic of zeotropic mixtures is the so-called 'temperature glide', $T_{g}$, of boiling phase changes and condensation, which means that phase transitions are not isothermal and they are accompanied 
with changes of the concentration of mixture components. The temperature glide of such a mixture is sometimes even approx. $10 \mathrm{~K}$. In contrast, NEARMs (Nearly Azeotropic Refrigerant Mixtures) have a small temperature glide and during the process of a phase transition they act as azeotropic (AZEO) mixtures. Another common feature of zeotropic mixtures is a nonlinear dependency course concerning temperature-enthalpy chart [18,31]. This may affect the intensity reduction of the heat flux density and the efficiency of the heat exchanger. The group of zeotropic mixtures include, among others R407C, however, R404A and R410A refrigerants belong to MBAs (nearly azeotropic refrigerant mixtures) mixtures. These mixtures represent high pressure refrigerants and share the following values of temperature glide: R404A - approx. $0.5 \mathrm{~K}$; R407C - approx. $7.2 \mathrm{~K}$; R410A - approx. $0.1 \mathrm{~K}$ [7]. The interaction of these characteristics of zeotropic mixtures with single-component refrigerants affects the diversity of condensation mechanism. In the process of condensation and boiling of these mixtures, there is a percentage change of components and also the phase transition temperature changes (for a homogeneous refrigerant phase transition temperature is constant, it depends on pressure $p=$ const.) It is a very complex phenomenon due to the dynamic mechanism of the percentage change depending on the saturation temperature and pressure in the refrigeration cycle, which cannot be predicted. The process of condensing of homogeneous agents theoretically is in a stable saturation temperature $T_{s}=f(p)$, which is a function of absolute pressure of the process. Due to these differences in the mechanisms of condensation, the appropriate calculation method must be chosen to determine the thermal and flow characteristics of such a mixture.

In the following part of the paper we present the results of the analysis of literature data and our own experimental studies on pressure drop and heat transfer during condensation of zeotropic mixtures in comparison to the uniform R134a refrigerant.

The authors of [25] presented the test results during the condensation of R22, R134a, and R410A refrigerants in a countercurrent heat exchanger type 'tube in tube'. The heat exchanger was made of copper minichannels with an internal diameter of $1.77,3.36$, and $5.35 \mathrm{~mm}$, while in these minichannels the refrigerant flows inside and water is in the space between tubes. The length of the test section was as follows: 1220, 2660, and $3620 \mathrm{~mm}$. The study was conducted with the mass flux density of 200$400 \mathrm{~kg} /\left(\mathrm{m}^{2} \mathrm{~s}\right)$ in the saturation temperature of $40^{\circ} \mathrm{C}$. The results showed 
that in the case of a mixture of R410A, with the comparable process parameters, the heat transfer coefficient was higher than that of R22 and R134a. The study also confirmed the influence of the internal diameter and the mass flow density on the intensity of heat transfer. The reduction of the internal diameter of a minichannel clearly influenced the intensification of the condensation process in the flow.

Rajan [23] in his paper on the basis of experimental boiling tests in the flow states that the heat transfer coefficient of R410A is approx. $30 \%$ higher than the R22. The big disadvantage of refrigerant R410A is a high pressure of this refrigerant in the system, higher by approx. $60 \%$ of R22.

The authors of publications [20,21] proposed their own, generalized mathematical model for description of heat transfer and pressure drop during condensation and boiling of refrigerants in the small diameter channels. The analysis covered such refrigerants, as R134a, R404a, R600a, R290, R32, and R1234yf. Based on the available research results the authors of the paper compared own mathematical models with correlations of other authors. In articles $[20,21]$ to evaluate the value of heat transfer coefficient and pressure drop during condensation were used correlations due to Thome et al., Cavallini et al., Matkovic et al., and Bohdal et. al., which they next compared to their own calculation model and test results. The comparison was made for R32, R404A and R134a refrigerants. The scope of minichannel internal diameter changes was $0.45-3.30 \mathrm{~mm}$. In all cases authors obtained satisfactory results of comparison with their own model.

Thome [28] presented the calculation model of heat transfer during the condensation of zeotropic mixtures in horizontal channels. He draws attention to three important issues concerning the condensation of mixtures, namely: 1) construction of new two-phase flow maps, 2) difference of heat transfer models of zeotropic mixtures and homogeneous refrigerants, 3) original heat transfer model concerning these mixtures. The author proposed a model which gives the possibility to calculate the heat transfer coefficient for single-component refrigerants and after applying the modification, it also refers to zeotropic mixtures. Two different mechanisms of heat transfer during the condensation in the flow were taken into consideration in this model, i.e., heat exchange by convection and by film condensation. In the first case the heat transfer process takes place along the channel under the influence of pressure gradient, and the second correction of the model refers to the upper part of the circumference of the tube which remains dry during the flow. 
The authors of [9] conducted the study of condensation of R134a and $\mathrm{R} 407 \mathrm{C}$ refrigerants in minichannels. On the basis of obtained results they confirmed that the condensation process of the zeotropic mixture $\mathrm{R} 407 \mathrm{C}$ proceeds differently than the condensation process of R134a. Therefore, the calculations concerning zeotropic refrigerant mixtures should take into account both heat associated with the cooling of the vapor and liquid phase, as well.

Condensation tests of binary mixtures R125/R32, R134a/R32, and ternary R32/R125/R134a, and R125/R143a/R134a in a smooth copper tube diameter of $9.52 \mathrm{~mm}$ and a length of $3.67 \mathrm{~m}$ are shown in the paper by Doerr et al. [15]. The study was conducted in terms of changing the mass flux 125$375 \mathrm{~kg} /\left(\mathrm{m}^{2} \mathrm{~s}\right)$ and the saturation temperature $30-40{ }^{\circ} \mathrm{C}$. It was shown that when the pressure drop is higher, we obtain lower heat transfer coefficient in comparison to R22 for all the mixtures.

In paper [11] there are discussed the results of frictional pressure drop of R236ae, R134a, and R410A during the adiabatic two-phase flow in the multiports, composed of channels with a hydraulic diameter of $1.40 \mathrm{~mm}$. The test results showed that pressure drop is correspondingly lower for the mixture R410A compared to R134a and R236ae while keeping the same performance parameters and the saturation temperature. The experimental test results were compared to the calculation results according to the correlation of other authors. They confirmed a small usefulness of tested models in the description of the condensation process of mixture R410A, due to too large discrepancy with the experiment.

The author [19] presented the experimental test results during boiling of R134a and R407C in the horizontal smooth channels with an inner diameter of $d=0.835$ and $2.00 \mathrm{~mm}$. The range of measured parameters was: mass flux $-G=200-400 \mathrm{~kg} /\left(\mathrm{m}^{2} \mathrm{~s}\right)$, saturation temperature $-T_{s}=5-15^{\circ} \mathrm{C}$, vapor quality $-x=0.2-0.8$, and heat flux $-q=5-15 \mathrm{~kW} / \mathrm{m}^{2}$. The analysis of test results showed that in the case of zeotropic mixture, the lower pressure drop was received in relation to a single-component R134a refrigerant.

In the paper by Zhang et al. [33] there are presented the test results of condensation of R22, R410A, and R407C refrigerants in individual minichannels with a circular inner diameter of 1.088 and $1.289 \mathrm{~mm}$, in the range of the following parameters: $T_{s}=30-40{ }^{\circ} \mathrm{C}, G=300-600 \mathrm{~kg} /\left(\mathrm{m}^{2} \mathrm{~s}\right)$, $x=0.1-0.9$. As it was expected, there was an increase of pressure drop with increasing flux density of the mass, $G$, and the mass quality $x$, but in a range in which $x \geq 0.8$, the effect is much less pronounced. It showed that 
there is a dependence between the pressure drop and the type of two-phase flow structure.

In order to expand the database, experimental research on heat transfer was conducted during the condensation of certain types of zeotropic mixtures. The experimental test results were used to prepare thermal characteristics of local relations and averaged heat transfer coefficient on the parameters of the process. Then the results were compared with other relations of other authors previously tested of the homogenous refrigerant R134a.

\section{Experiment and testing facility}

Thermal and flow characteristics made on a dedicated test bench, which is at the Laboratory of Heat Engineering and Refrigeration of the Department of Koszalin University of Technology. The measurement station was instrumented with a control-measurement device with the elements of the cooling system and the drive, which enabled calculation of the heat transfer coefficient and pressure drop during condensation of a single-component R134a refrigerant and zeotropic mixtures R404A, R407C and R410A. In all cases, the same research methodology was applied, which enabled us to compare the test results. The detailed description along with a discussion of each element is given in [12].

The essential element of the test bench was a part of a minichannel 1 (Fig. 1) with a circular diameter and a total length $L=1000 \mathrm{~mm}$, in which the process of heat transfer took place during condensation. In the schematic diagram of the experimental set-up, shown in Fig. 1, can be distinguished two cooperating parallel refrigeration systems, namely: singlestage cooling system charged by the compressing and condensing generator and the cooling system that works with a measurement section of a tube minichannel. The refrigerant with a preset and fixed in time thermal and flow parameters was connected to this section.

Control-measuring instrumentation of the test bench allowed to set the process parameters such as temperature of the refrigerant, cooling water temperature, temperature of the outer wall of a minichannel, mass flow density of the refrigerant and water, pressure of the refrigerant, pressure drop of a refrigerant on the length of a measurement section. 


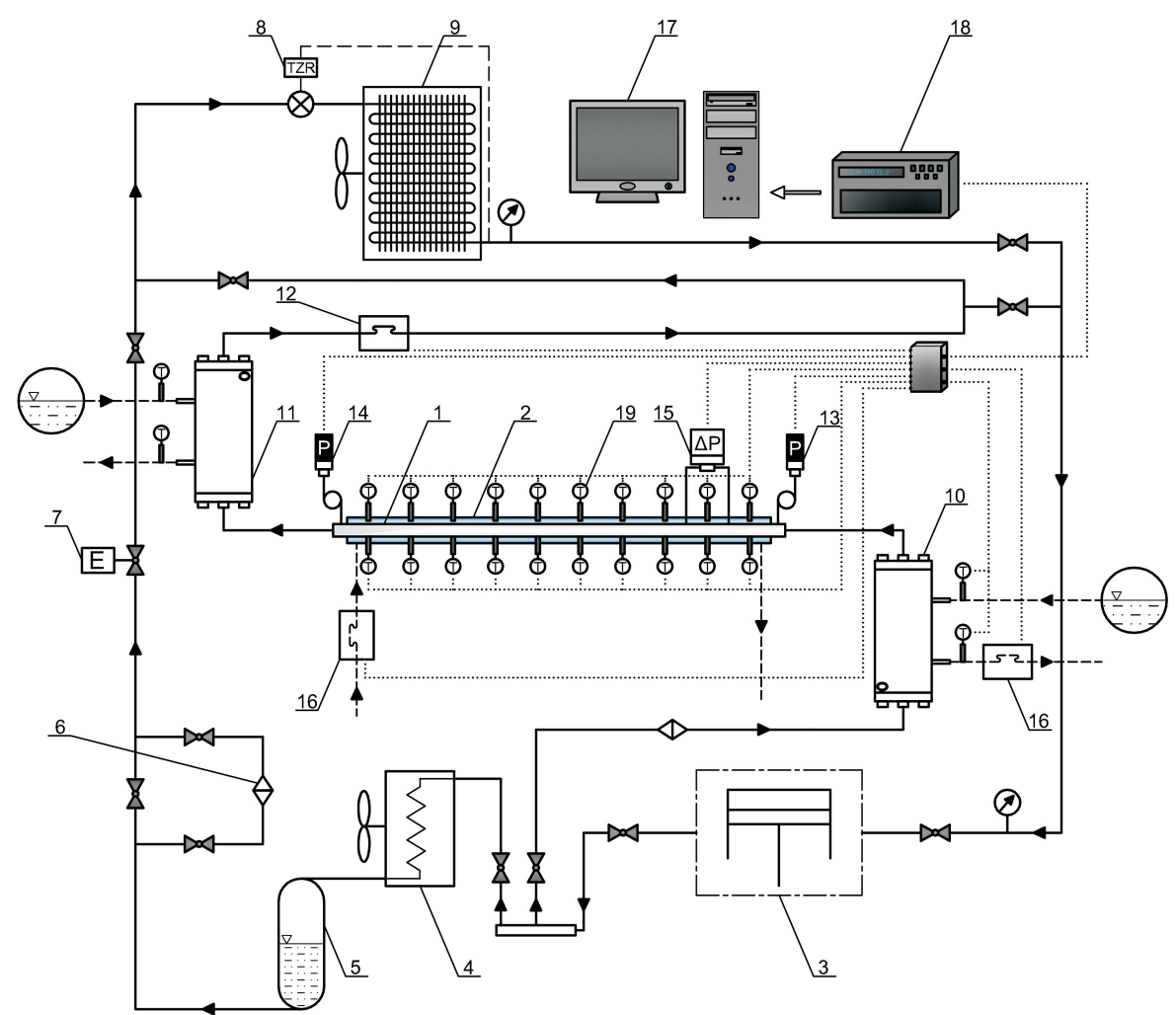

Figure 1: Schematic diagram of the test stand: 1 - measuring section of pipe minichannel, 2 - water channel, 3 - refrigeration compressor unit, 4 - air cooled condenser, 5 - tank of liquid refrigerant, 6 - filter-dryer of refrigerant, 7 - electromagnetic valve, 8 - thermostatic expansion valve, 9 - air cooler, 10 - heat exchanger for removal of superheating, 11 - liquid refrigerant subcooler, 12 - electronic flowmeter, 13 - pressure sensor of refrigerant on inlet to the test section, $14-$ pressure sensor of refrigerant at the outlet of the test section, 15 - differential pressure sensor, 16 - water flowmeter, 17 - computer, 18 - data acquisition system, 19 - temperature sensors (thermocouple type K).

Applying the heat balance method the heat flux, $q$, was determined indirectly. That enabled subsequent determination of the mass quality, $x$, and the heat transfer coefficient, $\alpha[13]$.

The thermal and flow research of refrigerants was made in the range of the following parameters:

- inner diameter of the tubular minichannel: $d=0.31-3.30 \mathrm{~mm}$,

- mass flux: $G=0-3500 \mathrm{~kg} /\left(\mathrm{m}^{2} \mathrm{~s}\right)$, 
- heat flux: $q=0-100 \mathrm{~kW} / \mathrm{m}^{2}$,

- saturation temperature: $T_{s}=20-40^{\circ} \mathrm{C}$,

- vapor quality: $x=1-0$.

The aim of the experimental, thermal and flow study, was to determine mean and local values of the heat transfer coefficient and pressure drop during condensation.

\section{$3 \quad$ Experimental test results}

The results of experimental studies led to the preparation of thermal and flow characteristics during the condensation in flow of R134A, R404A, R407C, and R410A refrigerants in minichannels. Experimental studies of condensation were conducted in averaged and local conditions for tube minichannels having an inner diameter of $0.31,0.45,0.64,1.40,1.92,2.00$, 2.30 , and $3.30 \mathrm{~mm}$, made of stainless steel. The conducted study aimed to determine the effect of parameter changes of the process and the properties of the refrigerant on heat transfer coefficient and pressure drop.

It is interesting to compare the characteristics of the condensation, depending on the type of the refrigerant. Figure 2 shows the example of comparative characteristics of the average heat transfer coefficient, $\alpha_{a}$, for such refrigerants as: R134A, R404A, R407C, and R410A. The test results indicate that for the internal diameter of a minichannel of 0.31 and $1.40 \mathrm{~mm}$, the maximum value of average heat transfer coefficient was obtained by one-component R134a refrigerant, but in the case of zeotropic mixtures the higher values of $\alpha_{a}$ were obtained by R407C, compared to R404A and $\mathrm{R} 410 \mathrm{~A}$. Meanwhile this increase is in the range of 10 to $15 \%$, and for channels less than $1 \mathrm{~mm}$ it is approx. $30-40 \%$.

Figure 3 illustrates an exemplary experimental thermal characteristics in the form of the dependence of local heat transfer coefficient on the vapor quality, $\alpha_{x}$, during condensation of zeotropic mixtures such as R404A, $\mathrm{R} 407 \mathrm{C}$ and R410A and homogeneous refrigerant R134a in pipe minichannels pipes with a diameter $0.31-0.90 \mathrm{~mm}$ and $2.30 \mathrm{~mm}$. The test results confirmed that the local heat transfer coefficient depends on both the internal diameter of the tubular minichannel, as well as the local vapor quality and mass flux. The decrease in a diameter of a minichannel influences the growth of $\alpha_{x}$ value significantly. 
a) $d=0.31 \mathrm{~mm}$

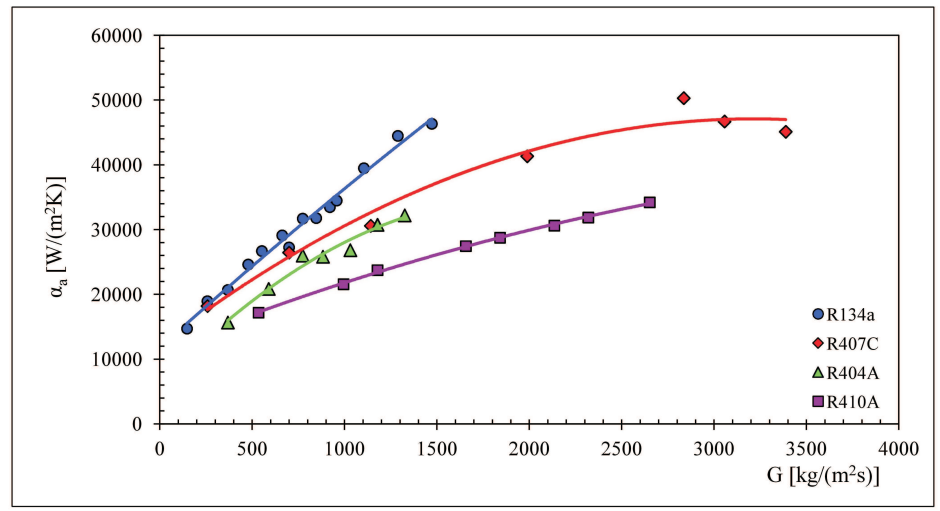

b) $d=1.40 \mathrm{~mm}$

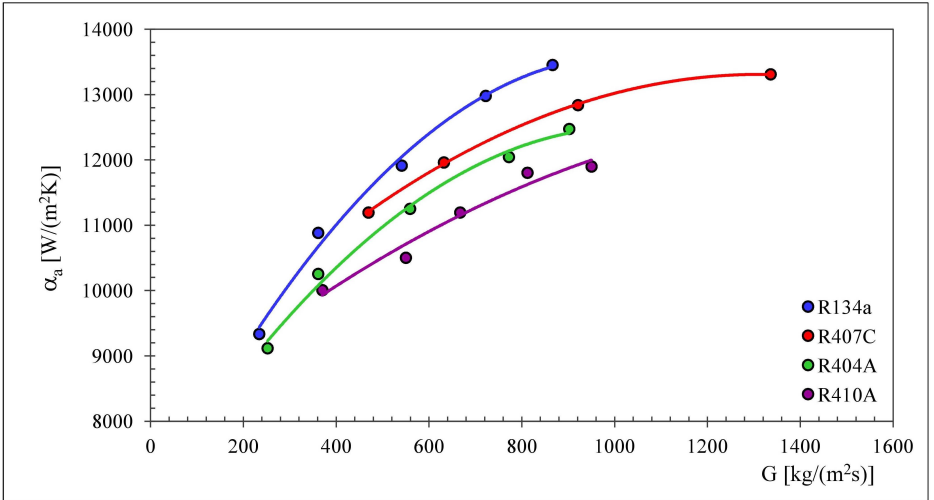

Figure 2: Example of experimental heat characteristics during condensation of R134A, R404A, R407C, and R410A refrigerants in averaged conditions for the dependence of heat transfer coefficient on the mass flux density, $\alpha_{a}$, for minichannels with an inner diameter of $0.31 \mathrm{~mm}(\mathrm{a})$, and $1.40 \mathrm{~mm}(\mathrm{~b})$ for $x_{a}=0.8$.

By analyzing the characteristics in Fig. 3 it is noticed that there is a significant influence of the change of the local vapor quality (with $G=$ const) on the course of characteristics. The decrease in the vapor quality is initially followed by a slight increase in the local heat transfer coefficient (in some cases), and after reaching the maximum value at $x \approx 0.8$, there is a substantial decline. This especially refers to minichannels with the internal diameter of less than $1 \mathrm{~mm}$.

The analyzed thermal characteristics (Fig. 4) concerning condensing of the homogeneous refrigerant (R134a) and zeotropic mixtures (R404A, 
a)
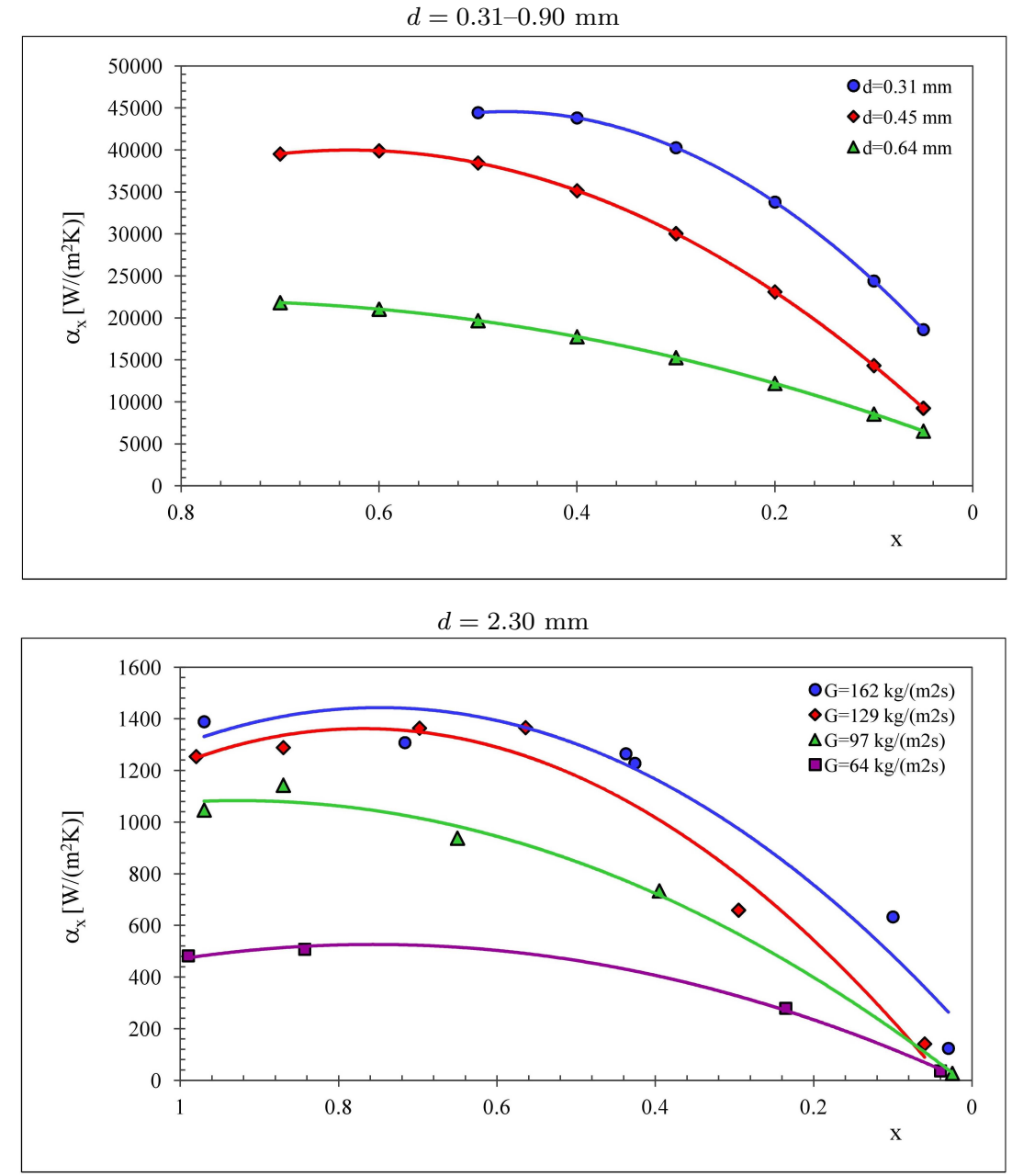

Figure 3: Comparison of experimental thermal characteristics concerning condensation of refrigerants in local conditions; dependence of local heat transfer coefficient on vapor quality, $\alpha_{x}=f(x)$, for minichannels with a diameter of $0.31-0.90 \mathrm{~mm}$ and $2.30 \mathrm{~mm}$, when $G=$ const, for refrigerants: a) R134a.

R407C and R410A) have a similar course. The lowest obtained values were achieved by R410A.

For all tested refrigerants we have made the characteristics describing the local and the average pressure drop value, $(\Delta p / L)$, of the vapor quality, $x$, the mass flux, $G$, and the inner diameter of a minichannel, $d$, (Figs. 5-7 the 
b)

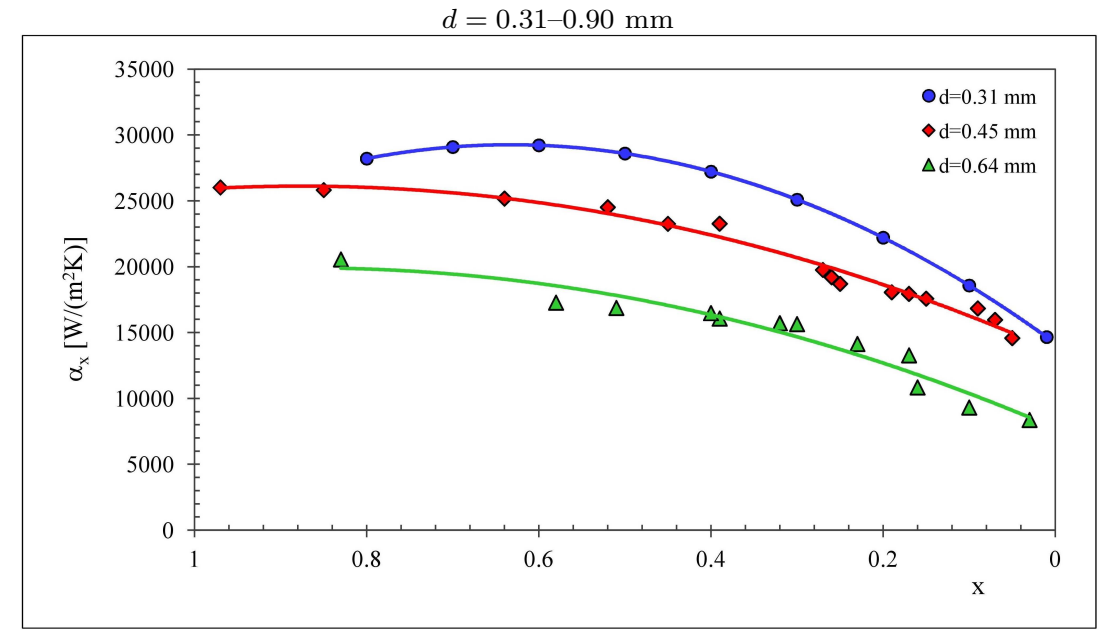

$d=2.30 \mathrm{~mm}$

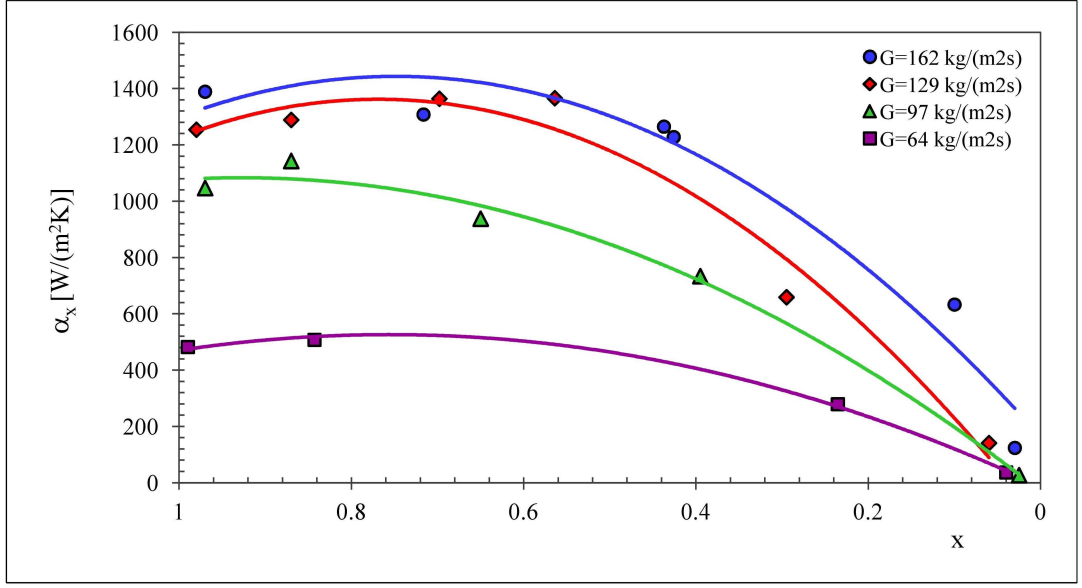

Fig. 3 continued: b) R404A. For caption see p.51.

average values were calculated for proper condensing zone (in the range of $x=0-1$ ), while the local pressure drop was measured at nine cross-sections separated from one another every $100 \mathrm{~mm}$.

The reduction of the minichannel inner diameter significantly affects the increase in pressure drop during condensation. It can be seen that the increase of pressure drop is related to the decrease of the inner diameter. However, the pressure drop grows very rapidly when the diameter decreases below $1 \mathrm{~mm}$. This is the effect of increasing influence of surface tension 
c)
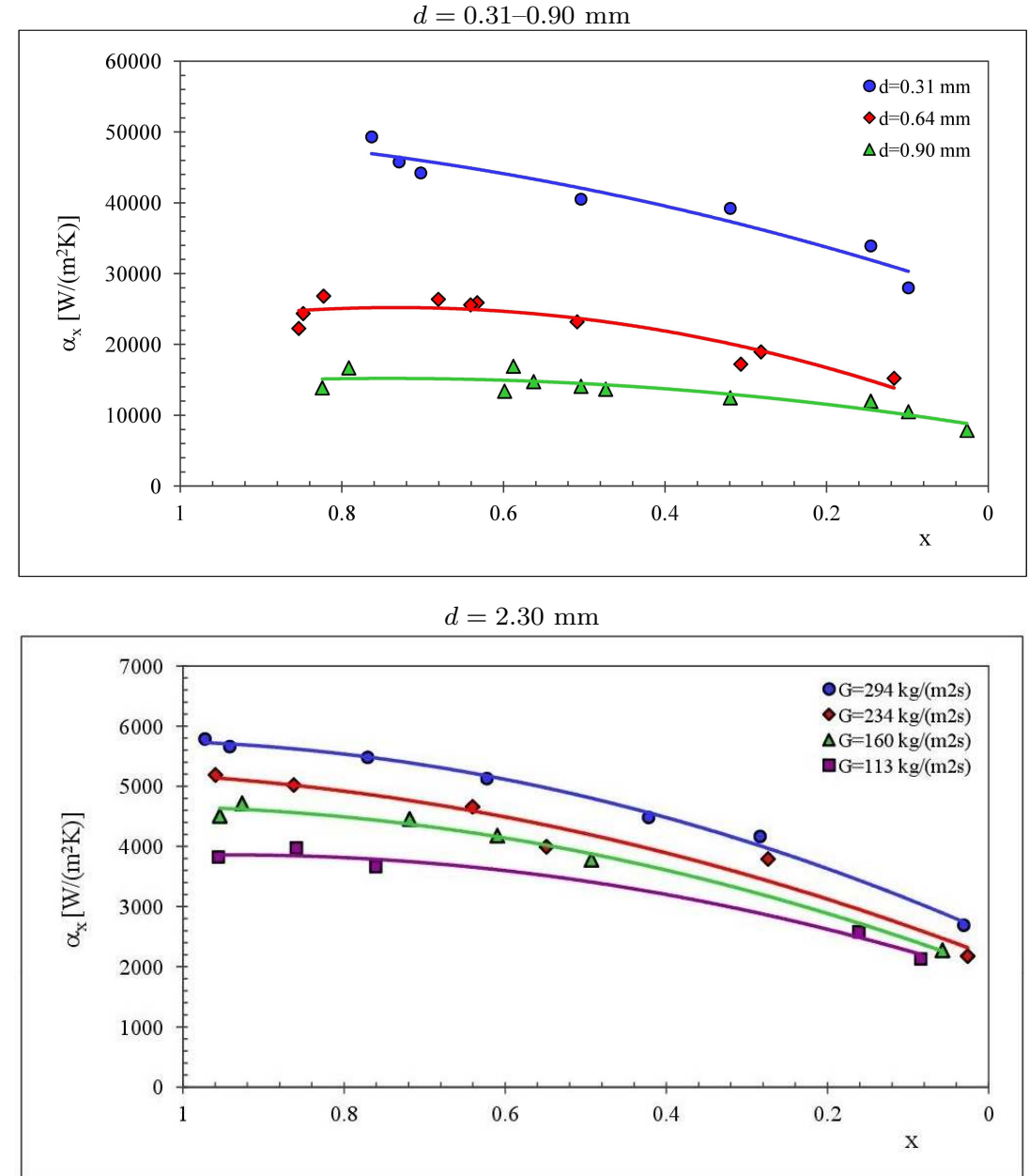

Fig. 3 continued: c) R407C. For caption see p.51.

and viscosity forces on friction. The increase in pressure drop is unfortunately connected with the increase of driving energy demand. It is an undesirable effect. 
d)

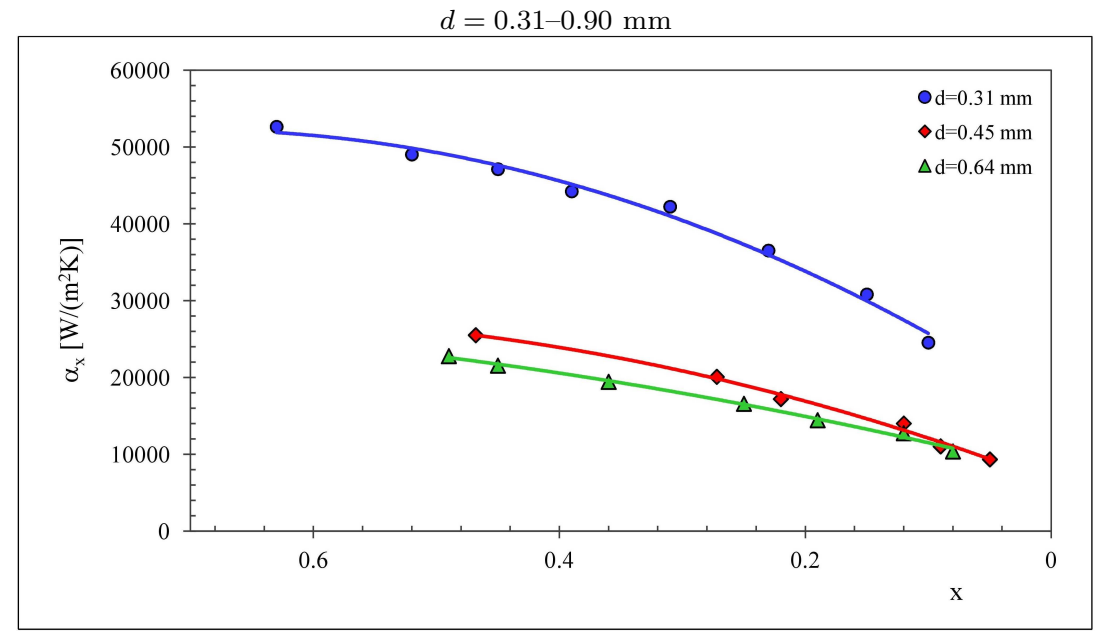

$d=2.30 \mathrm{~mm}$

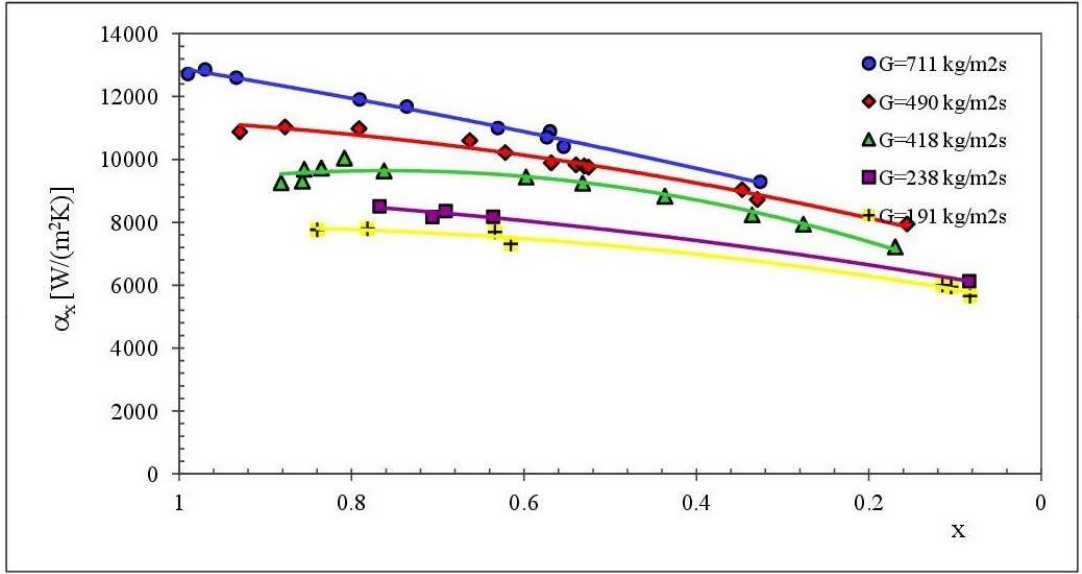

Fig. 3 continued: d) R410A. For caption see p.51.

\section{Analysis of experimental results}

The results of our study of local pressure drop, $(\Delta p / L)_{x}$, and heat coefficient, $\alpha_{x}$, were compared with the calculation results according to the correlation of other authors, for four tested refrigerants R134a, R404A, R407C, and R410A in minichannels of a diameter $d=0.31-3.30 \mathrm{~mm}$. In the case of heat transfer coefficient, we used the correlation of Akers [2], and Shah [24], Tang [26], Thome [29], Mikielewicz [21], and Cavallini [8]. The dependency 


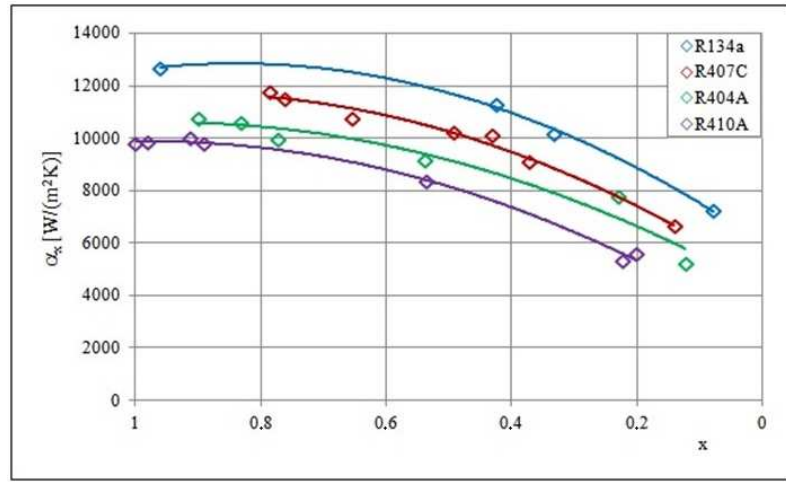

Figure 4: Comparison of the dependence of heat transfer coefficient on vapor quality of condensation in local conditions for a homogenous refrigerant R134a and zeotropic mixtures R404A, R407C, and R410A in minichannels with an inner diameter of $1.40 \mathrm{~mm}$, when $G=$ const.
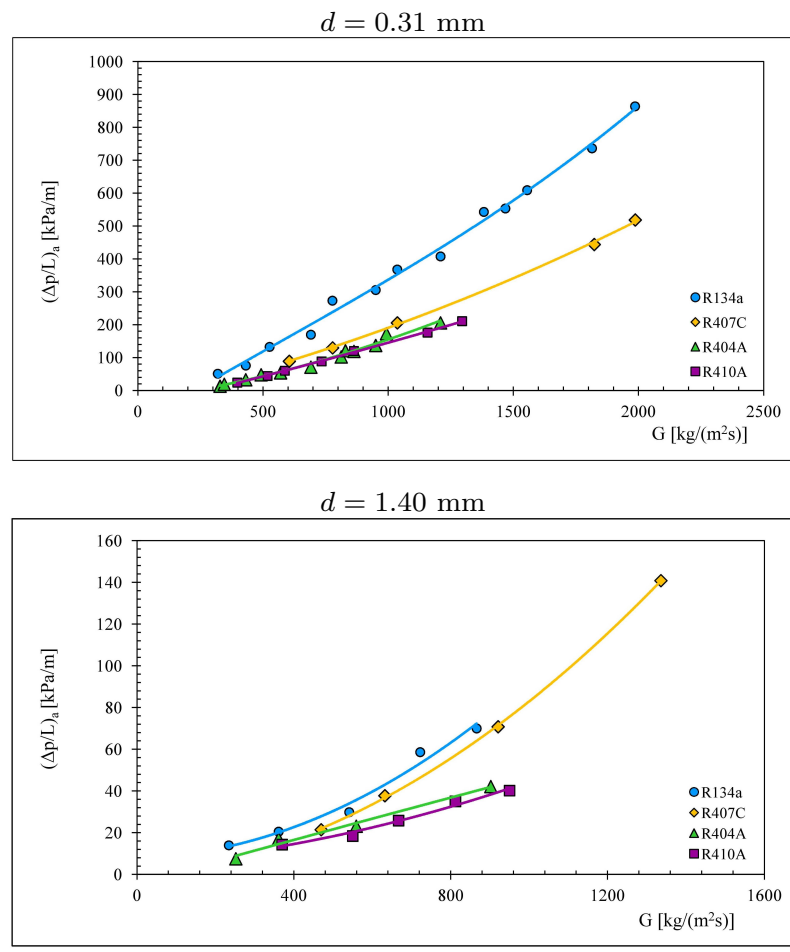

Figure 5: Experimental flow characteristics of the condensation of R134a, R404A, R407C, and R410A refrigerants in averaged conditions; dependence of average pressure drop on the mass flux, $(\Delta p / L)_{a}$, for minichannels with an inner diameter of $0.31 \mathrm{~mm}$ and $1.40 \mathrm{~mm}$, for $x_{a}=0.8$. 
a)

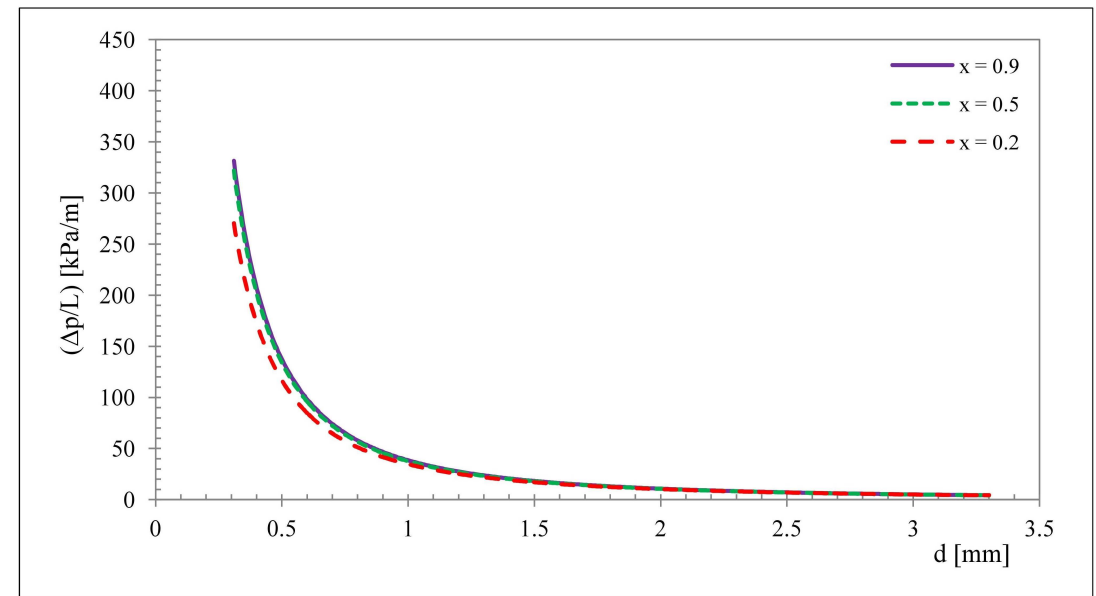

b)

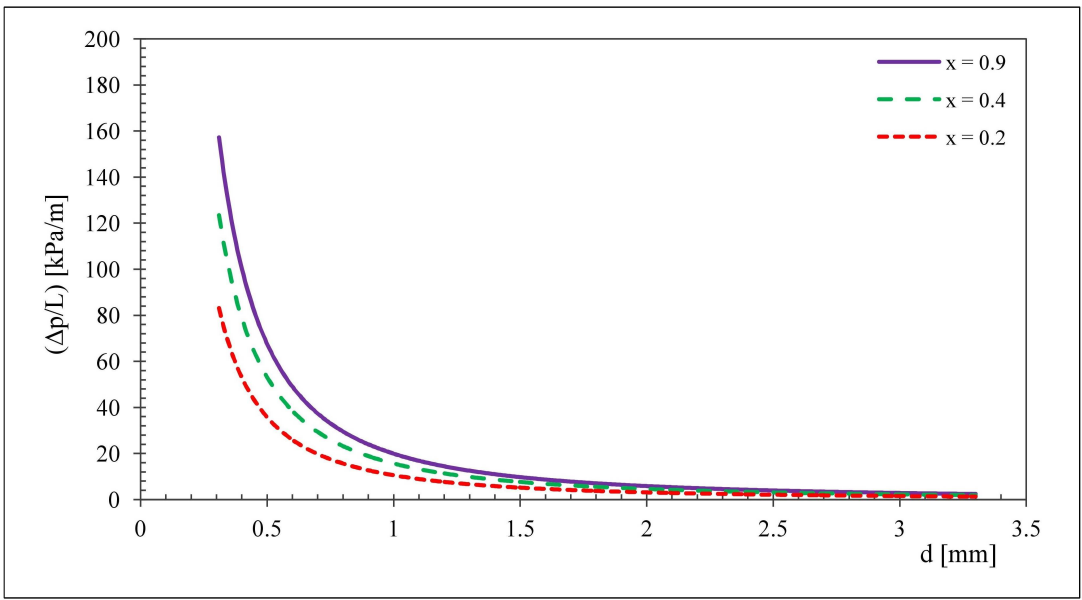

Figure 6: Comparison of the dependence of local pressure drop values, $(\Delta p / L)_{x}$, on the innernal diameter of a minichannel with $G=300 \mathrm{~kg} /\left(\mathrm{m}^{2} \mathrm{~s}\right)$ and $x=$ const for tested refrigerants: a) R134a, b) R404A.

of experimental results with the calculation results depends on both the internal diameter of a minichannel and the mass flux. The analysis showed that the experimental results of the coefficient heat transfer correspond well with the calculated results by the correlation of Shah [24] and Akers et al. [2]. As for the mass flux $G<600 \mathrm{~kg} /\left(\mathrm{m}^{2} \mathrm{~s}\right)$ the better approximation is achieved by the usage of Akers correlation, and at $G>600 \mathrm{~kg} /\left(\mathrm{m}^{2} \mathrm{~s}\right)$ the 
c)

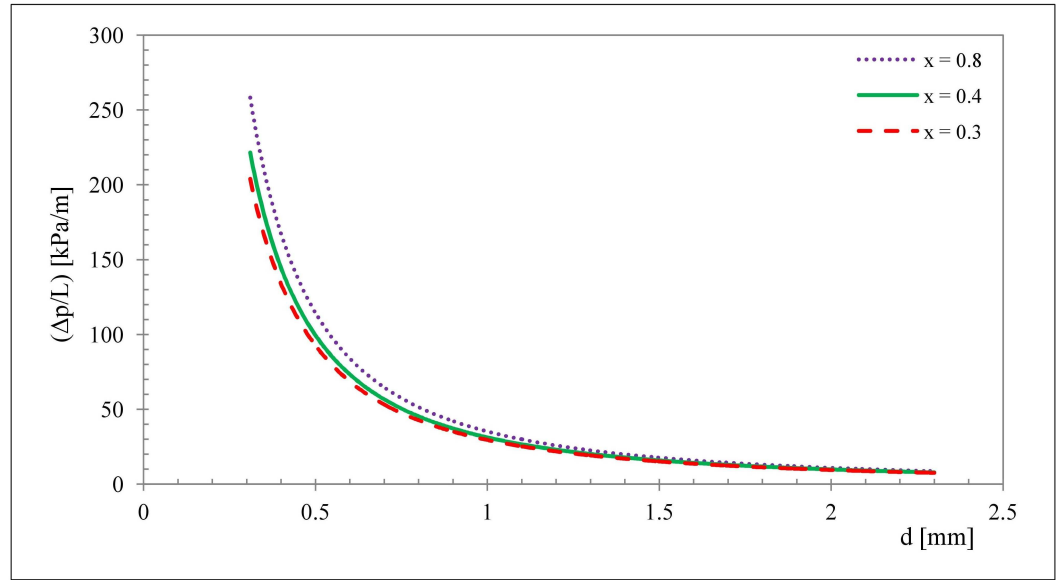

d)

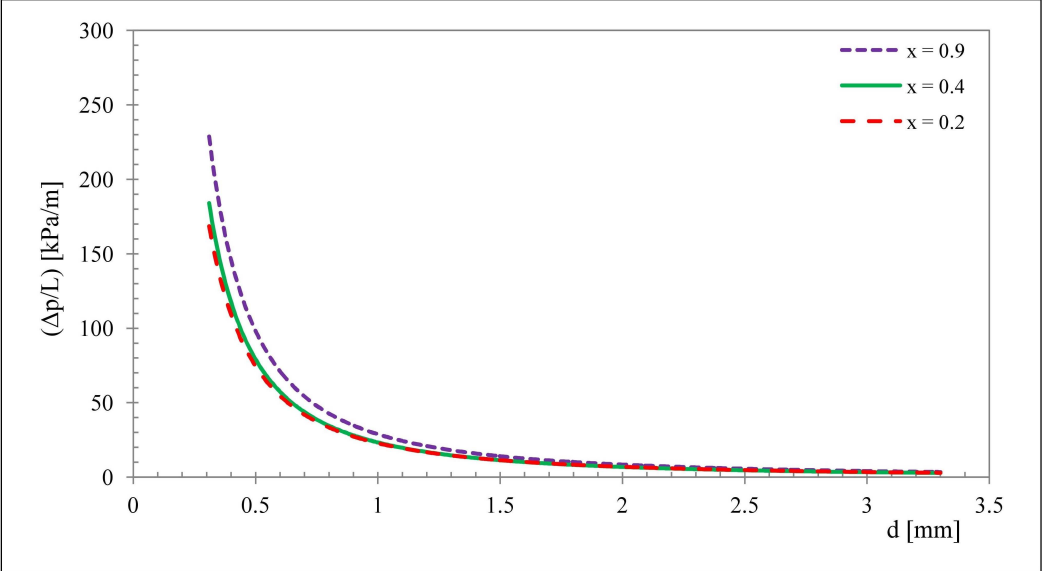

Fig. 6 continued: c) R407C, d) R410A. For caption see p. 56.

results of experiments are better described by Shah correlation, especially for minichannels with higher values of diameter. It should be emphasized that in whole range of mass flux of condensed refrigerant the best accuracy was observed with Mikielewicz correlation. This equation is recommended for calculations of compact heat exchangers. Figure 8 shows a comparative summary of the test results with the calculation results by correlations of: a) Shah [24], b) Akers [2], c) Tang [26], d) Thome [29] Mikielewicz [21] and Cavallini [8], for the four tested refrigerants R134a, R404A, R407C, and R410A. 
a)

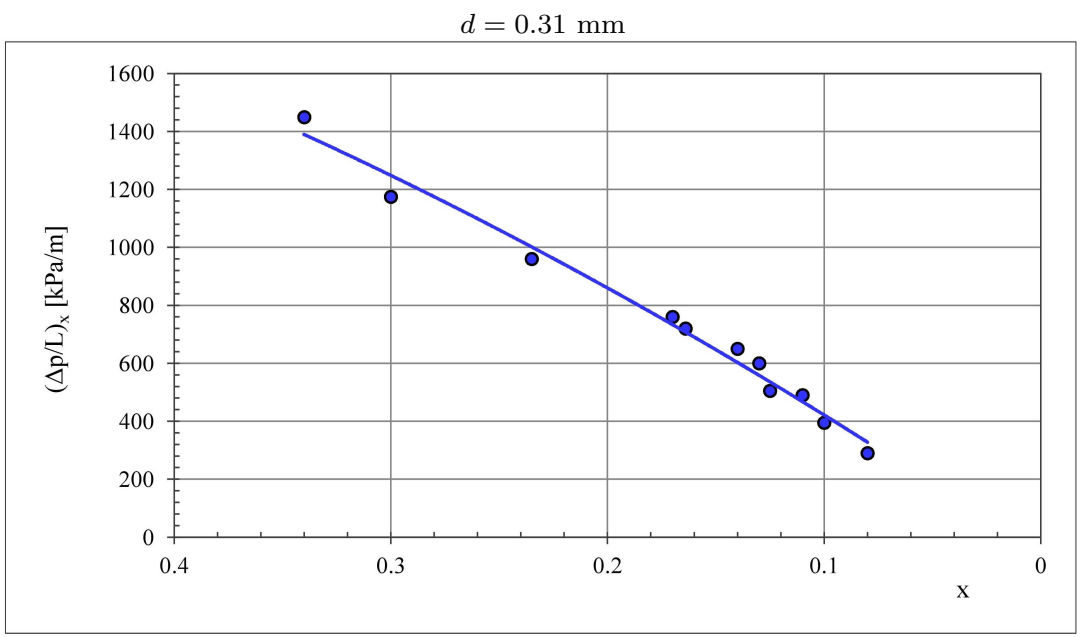

$d=1.40 \mathrm{~mm}$

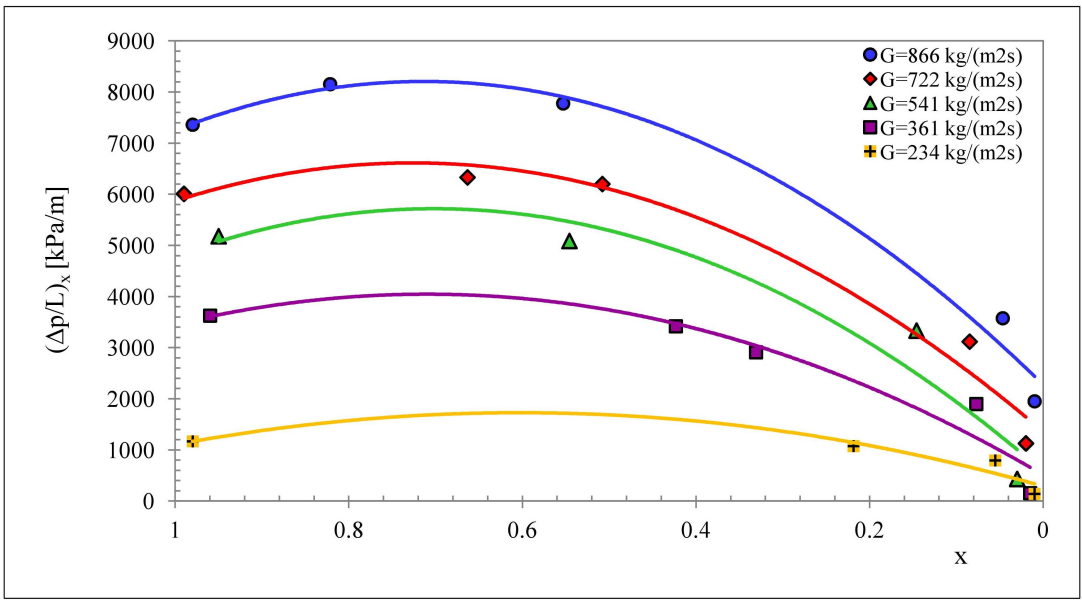

Figure 7: Summary of experimental flow characteristics of the refrigerants condensation in local conditions for the dependence of the pressure drop on the vapor quality, $(\Delta p / L)_{x}$, for minichannels with a diameter of $0.31 \mathrm{~mm}$ and $1.40 \mathrm{~mm}$, with $G=$ const for: a) R134a. 
b)
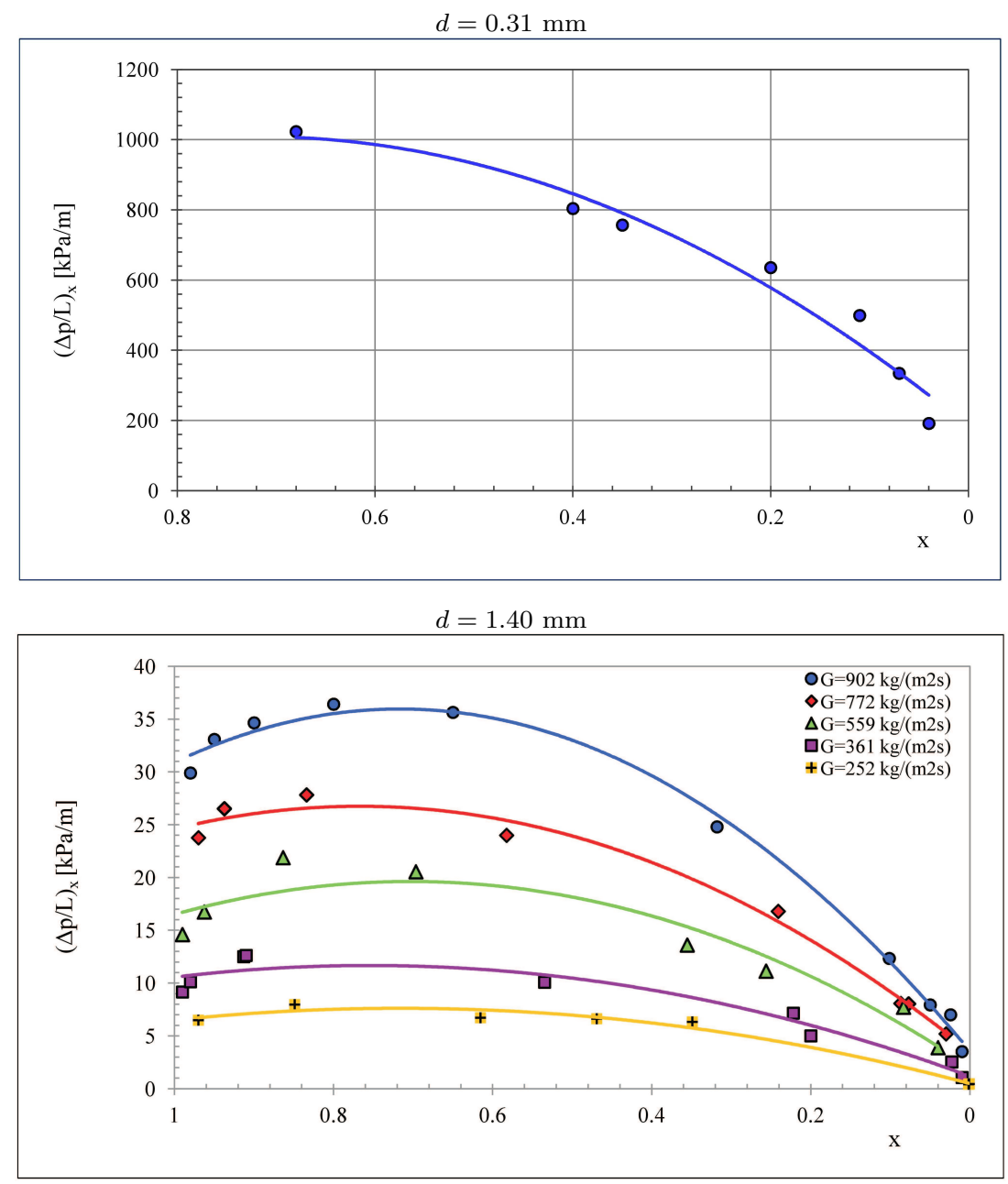

Fig. 7 continued: b) R404A. For caption see p. 58 . 
c)
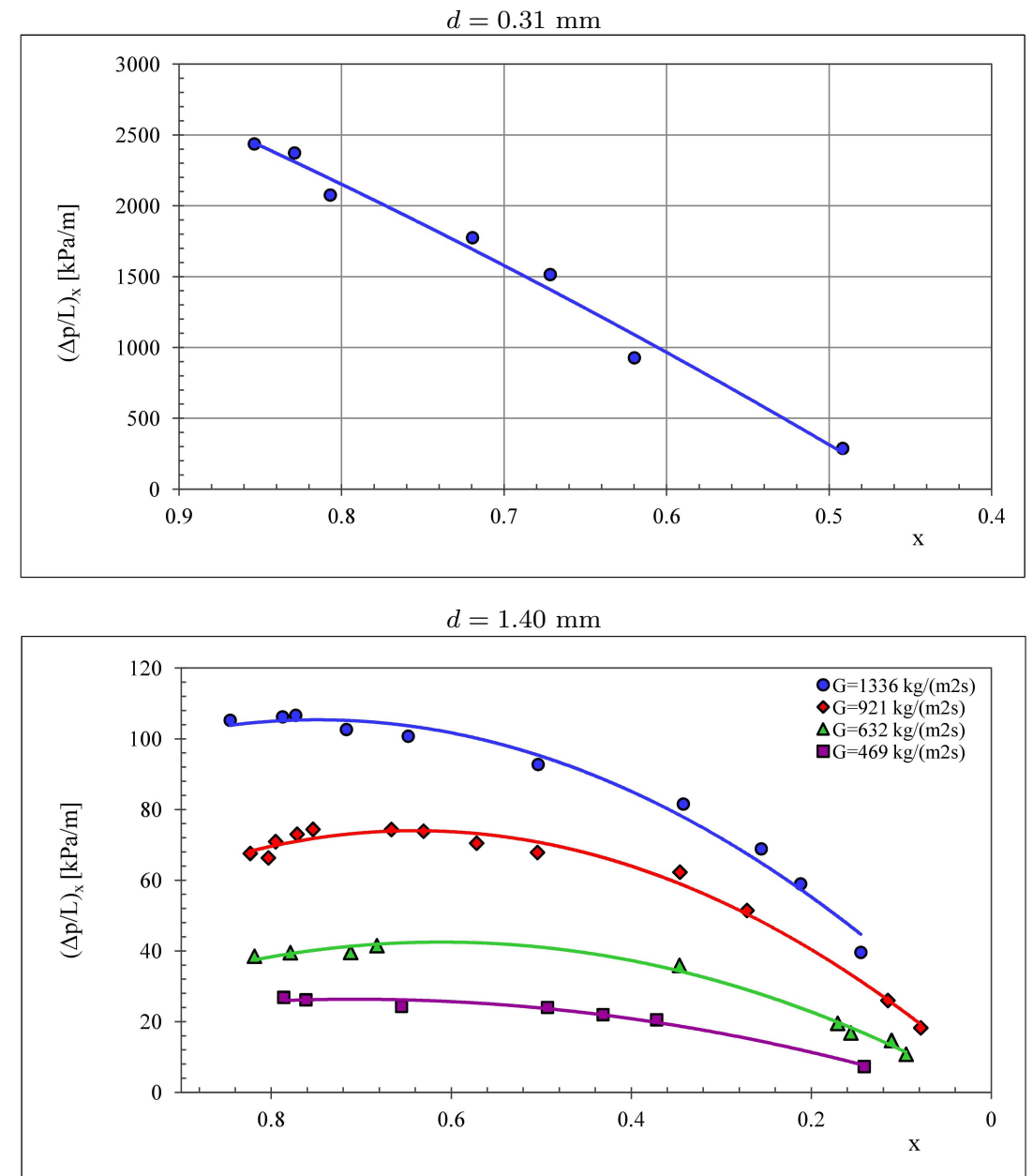

Fig. 7 continued: c) R407C. For caption see p .58. 
d)
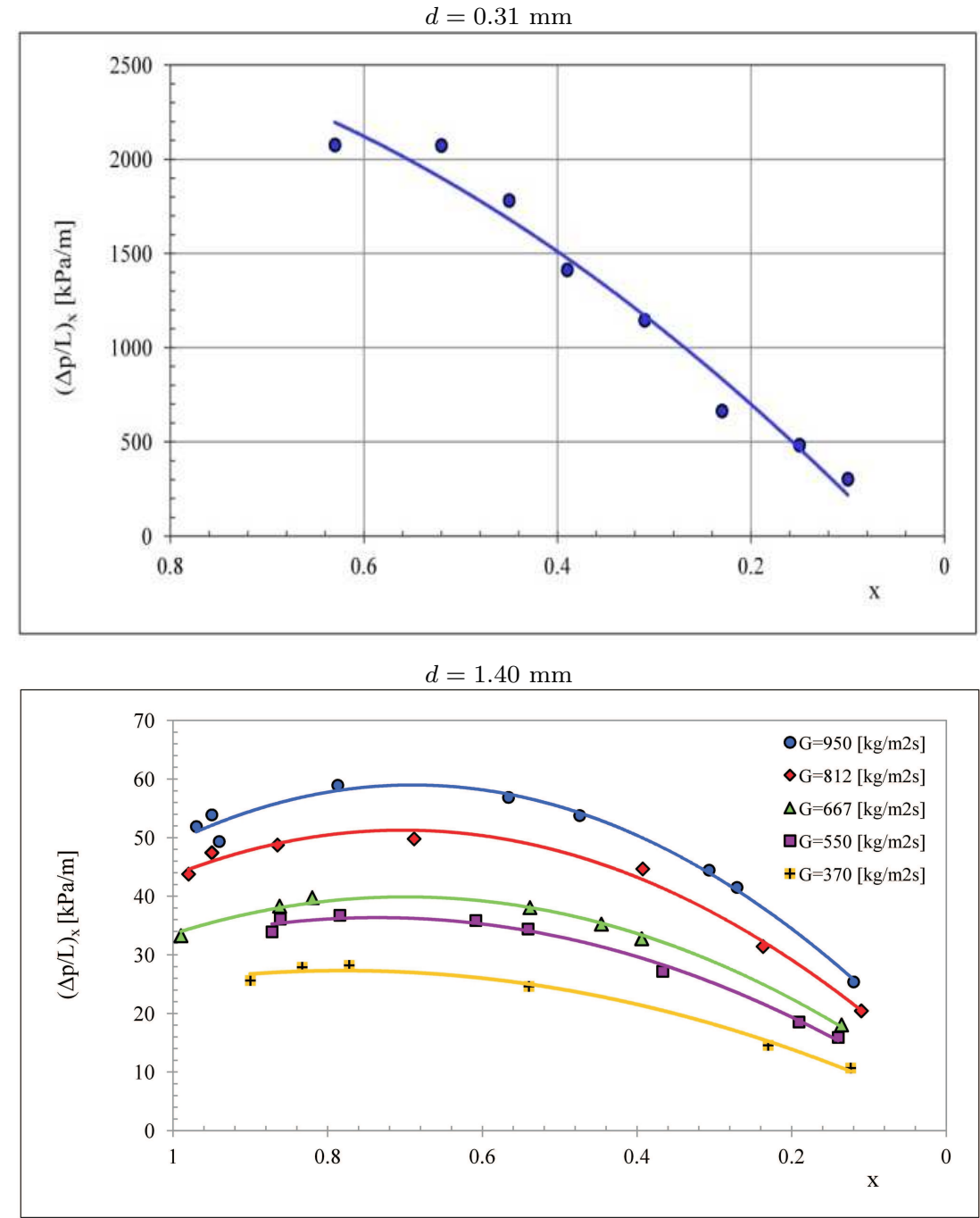

Fig. 7 continued: d) R410A. For caption see p. 58. 
Figure 9 summarizes the results of experimental studies in comparison to the calculation results obtained using the correlation developed by other authors for the local pressure drop. These were the comparative models due to Friedel [16], Garimella [17], Cavallini [10], Chen [14], Mikielewicz [20], and Zhang and Webb [32]. Discrepancies between own investigation results and the calculation results using mentioned above correlations, were found in the range of $50 \%$. In Fig. 9 is shown that experimental results are most closely following the calculation results (in the same parameters range) obtained using Friedel, Garimella, and Mikielewicz correlations. It is a satisfactory result. The most of points is found in the discrepancy of $\pm 50 \%$, which confirms that these equations can be recommended for the design calculations of pressure drops. In the case of heat transfer coefficient the usefulness of described correlations is limited.

Relatively large divergences between experimental tests and the calculations using correlation of other authors made it necessary to develop own universal experimental model based on own data analysis and literature describing the local process of heat and pressure drop during condensation of zeotropic mixtures in tube minichannels. On the basis of the dimensional analysis and the theory of similarity, with the application of the nonlinear regression model, we have calculated the correlation equations describing the local Nusselt number $\mathrm{Nu}_{x}$ and the local flow resistance pressure drop $(\Delta p / L)_{x}$ as in $[5,6]$

$$
\begin{gathered}
\mathrm{Nu}_{x}=25.084 \operatorname{Re}_{l}^{0.258} \operatorname{Pr}_{l}^{-0.495} p_{r}^{-0.288}\left(\frac{x}{1-x}\right)^{0.266,}, \\
p_{r}=\frac{p_{s}}{p_{c r}},
\end{gathered}
$$

where: $p_{r}$ - reduced pressure, $p_{s}$ - saturation pressure, $p_{c r}$ - critical pressure. The dimensional form of Eq. (2) can be written as:

$$
\alpha_{x}=\frac{\mathrm{Nu}_{x} \lambda_{l}}{d},
$$

where: $\lambda_{l}$-thermal conductivity of liquid refrigerant $[\mathrm{W} / \mathrm{mK}]$.

In the Eq. (2) there appears reduced pressure, $p_{r}$, which enable to extend application of Eq. (1) for average and high refrigerants, including such refrigerants as R404A, R407C and R410A.

The described correlation by the formula (1) has been previously tested for tube minichannels with a diameter from the range $0.9-3.30 \mathrm{~mm}$, mass 


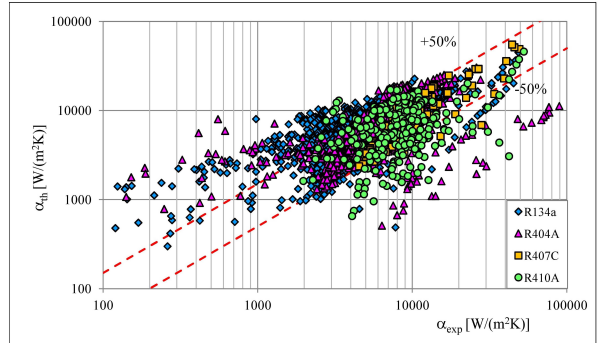

a)

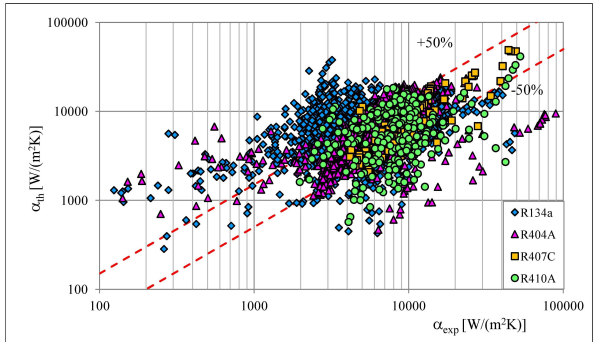

c)

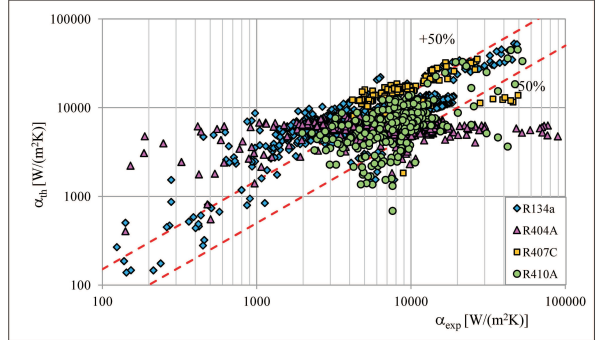

e)

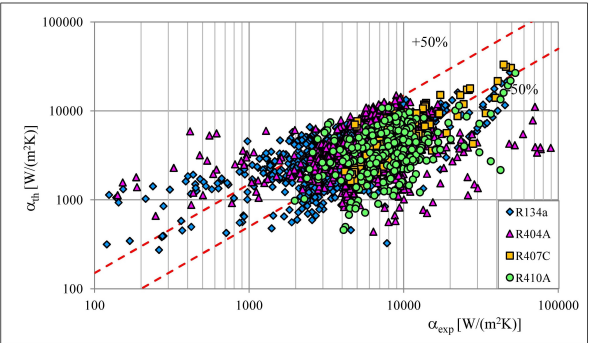

b)

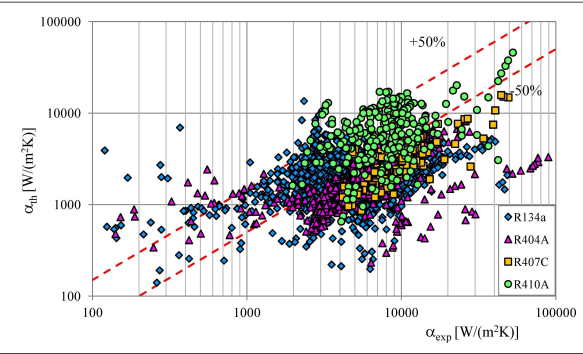

d)

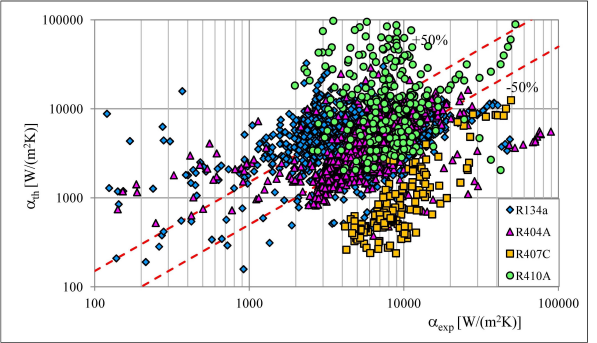

f)

Figure 8: Comparison of experimental thermal characteristics of the condensation of refrigerants in minichannels and the calculation results from the correlations: a) Shah [24], b) Akers [2], c) Tang [26], d) Thome [29], e) Mikielewicz [21], f) Cavallini $[8]$.

flux $100-1300 \mathrm{~kg} /\left(\mathrm{m}^{2} \mathrm{~s}\right)$ and saturation temperature $20-40{ }^{\circ} \mathrm{C}$, and during the condensation of the zeotropic mixture R404A and refrigerant R134a [4].

To describe the local pressure drop values we have proposed the following correlation [13]: 


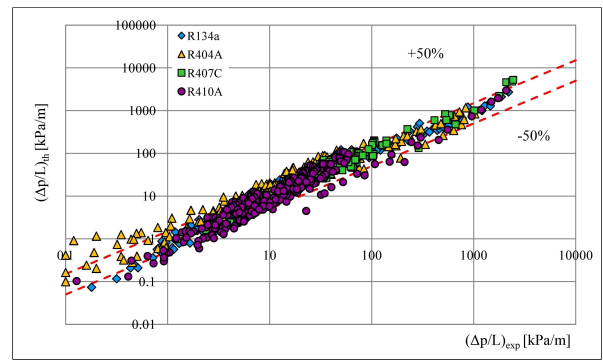

a)

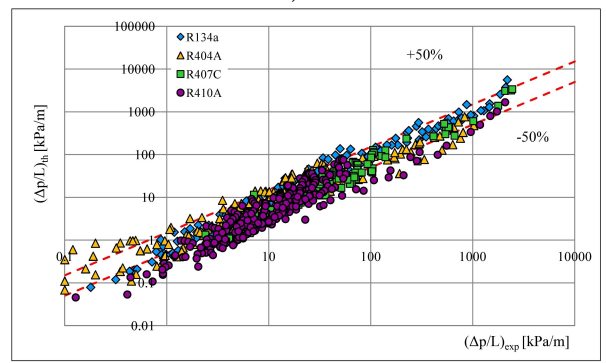

c)

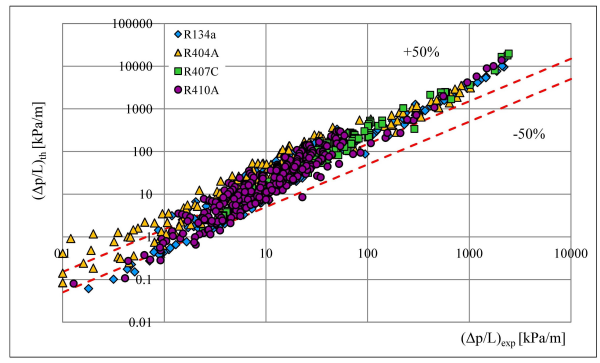

e)

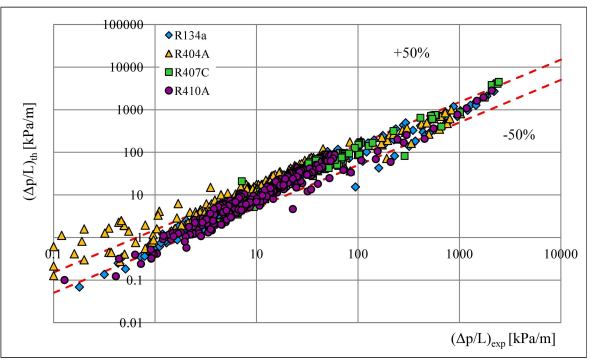

b)

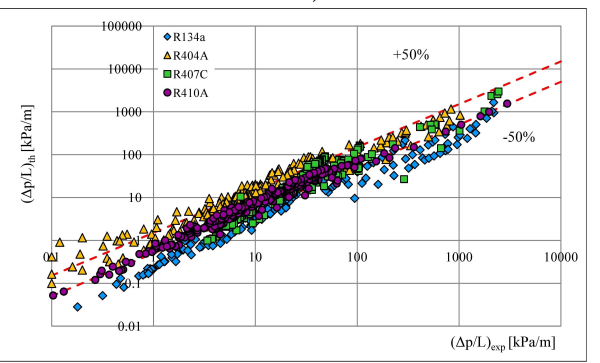

d)

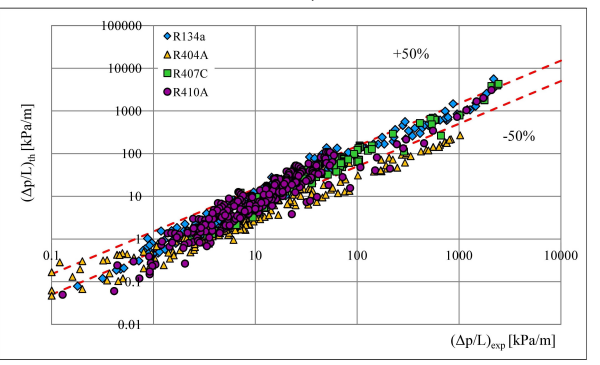

f)

Figure 9: Comparison of experimental flow characteristics of the refrigerants condensation in minichannels and the calculation results from the correlations: a) Friedel

[16], b) Garimella [17], c) Cavallini [10], d) Chen [14], e) Mikielewicz [20], f) Zhang and Webb [32].

$$
\left(\frac{\Delta p}{L}\right)_{T P F}=\left(\frac{\Delta p}{L}\right)_{l o}\left[0.003 p_{r}^{-4.722} E^{-0.992}+143.74\left(\frac{F^{0.671} H^{-0.019}}{\mathrm{We}^{0.308}}\right)\right]
$$

where 


$$
\begin{gathered}
E=(1-x)^{2}+x^{2}\left(\frac{\rho_{l}}{\rho_{g}}\right)\left(\frac{f_{g o}}{f_{l o}}\right), \\
F=x^{0.98}(1-x)^{0.24}, \\
H=\left(\frac{\rho_{l}}{\rho_{g}}\right)^{0.91}\left(\frac{\mu_{g}}{\mu_{l}}\right)^{0.91}\left(1-\frac{\mu_{g}}{\mu_{l}}\right)^{0.7}, \\
\mathrm{We}=\frac{G^{2} d}{\sigma \rho_{g}},
\end{gathered}
$$

wherein $f_{l o}$ and $f_{g o}$ friction coefficients are determined for a single-phase flow for the liquid and gaseous phases respectively, from the dependence of Baroczy [3] with the following form:

$$
f_{x}=8\left[\left(\frac{8}{\mathrm{Re}_{x}}\right)^{12}+\left\{\left[2.457 \ln \left(\frac{\mathrm{Re}_{x}}{7}\right)^{0.9}\right]^{16}+\left(\frac{37530}{\mathrm{Re}_{x}}\right)^{16}\right\}^{-1.5}\right]^{\frac{1}{12}}
$$

where the subscript $x$ stand for $l o$ for the liquid phase and $g o$ for the vapor phase.

In Fig. 10 comparison of investigation and calculation results are shown. It has been found that there is a compatibility of the results of experimental studies of heat transfer and pressure drop during the condensation of zeotropic mixtures R404A, R407C, and R410A and homogeneous refrigerant R134a with the calculations according to the correlation (3) and (4) in terms of discrepancies $\pm 25 \%$, which is considered to be a satisfactory result.

\section{Conclusions}

1. The thermal and flow experimental investigations of zeotropic mixtures - R404A, R407C and R410A - condensation in pipe minichannels in terms of the channel internal diameter changes $0.31-3.30 \mathrm{~mm}$.

2. The thermal characteristics condensing of refrigerants describing the dependencies of a heat transfer coefficient local and averaged value depending on the mass quality and mass flow density. On this basis, it has been shown that the heat transfer coefficient depends on thermal parameters of the condensation process (including saturation 


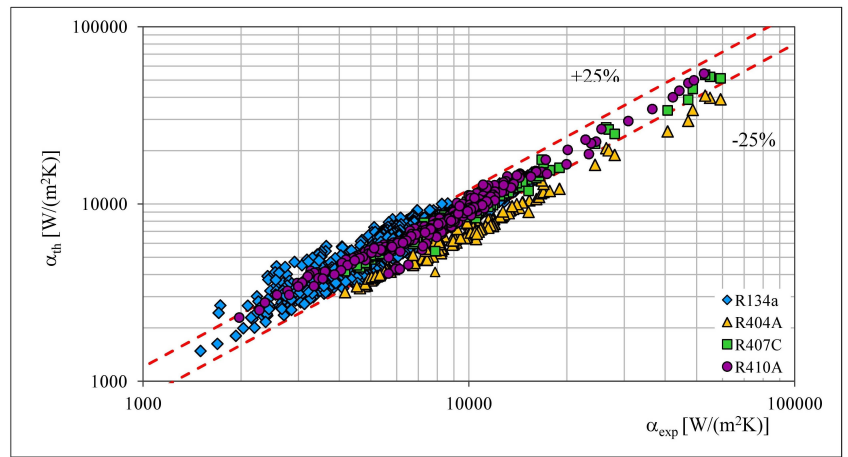

a)

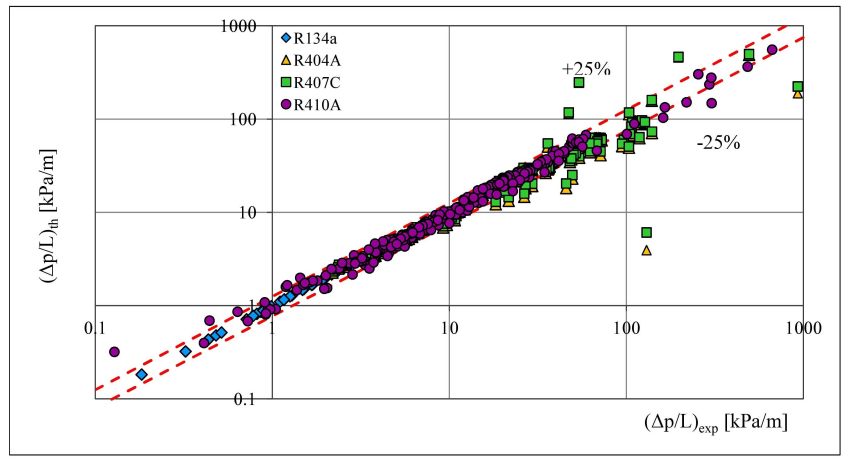

b)

Figure 10: Comparison of experimental investigation results with calculation results from authors own correlation: a) for Eqs. (1) and (3), b) for Eq. (4).

temperature), inner diameter of the tubular minichannel, mass flux and the vapor quality.

3. The characteristics describing the local values of pressure drop have confirmed that when there is a decline in the value of mass quality, there is an increase in local value of pressure drop and next there is a decrease. Local pressure drop also depends on the diameter of a minichannel. The increase in mass flux density results in the increase of the local pressure drop of condensable zeotropic mixtures.

4. The thermal and flow characteristics of the tested zeotropic mixtures were compared with the calculation results according to the correlation of other authors. As a result of calculations, the divergences of experimental results exceed the range of $\pm 50 \%$. 
5. The experimental correlation which allows us to calculate the value of the local heat coefficient and pressure drop during the condensation has been developed. The compiled model in the model accurately describes the process of condensation of both homogenous refrigerants (R134a) and zeotropic mixtures R404A, R407C, and R410A in tube minichannels. The proposed correlation is consistent with experimental results in the range of $\pm 25 \%$ and can be recommended for thermal design of compact minicondensers.

6. The investigated refrigerants were zeotropic mixtures with temperature glide.

Received 22 September 2015

\section{References}

[1] Akasaka R., Tanaka K., Higashi Y.: Thermodynamic property modeling for 2,3,3,3-tetrafluoropropene (HFO-1234yf). Int. J. Refrig. 33(2010), 52-60.

[2] Akers W., Deans O.K., Crosser O.K.: Condensation heat transfer within horizontal tubes. X Chem. Eng. Prog. 54(1985), 89-90.

[3] BARoczy C.J.: Correlation of liquid fraction in two-phase flow with applications to liquid metals. Chem. Eng. Prog. Symp. 61(1965), 179-191.

[4] Bohdal T., Charun H., Sikora M.: Comparative investigations of the condensation of $R 134 a$ and $R 404 A$ refrigerants in pipe minichannels. Int. J. Heat Mass Trans. 54(2011), 9-10, 1963-1974.

[5] Bohdal T., Charun H., Sikora M.: Experimental thermal-hydraulic characyterstics of condensation of zeotropic mixtures in canventional channels and minichannels. Chłodnictwo 6(2013), 14-19 (in Polish).

[6] Bohdal T., Charun H., Sikora M.: Pressure drop during condensation of refrigerants in pipe minichannels. Arch. Thermodyn. 33(2012), 1, 87-106.

[7] Bonca Z., Burtymowicz D., Targański W., Hajduk T.: New refrigerants and heat carriers. Thermal, chemical and application properties. A handbook. IPPU MASTA, Gdańsk 2004 (in Polish).

[8] Cavallini A., Censi G., Del Col D., Doretti L., Longo G.A., Rossetto L.: Experimental investigation on condensation heat transfer and pressure drop of new $H F C$ refrigerants (R134a, R125, R32, R410A, R236ea) in a horizontal smooth tube. Int. J. Refrig. 24(2001), 73-87.

[9] Cavallini, Cenesi G., Del Col D., Doretti L., Rossetto L.: Heat transfer coefficient HFC refrigerant turing condensation at high temperature inside a enhance tube. Proc. Int. Refrig. Conf. AT Purdue Univ., West Lafayette 2002. 
[10] Cavallini, Censi G., Del Col D., doretti L., Longo G.A., Rossetto L.: Condensation of halogenated refrigerants inside smooth tubes. HVAC \& Res.8(2002), 4, 429-451.

[11] Cavallini, Del Col D., Doretti L., Matkovic M., Rossetto L., Zilio C.: Two - phase frictional pressure gradient of R236ea, R134a and R410A inside multiport minichannels. Exp. Therm. Fluid Sci. 29(2005), 861-870.

[12] Charun H.: Experimental methods of heat transfer investigations during phase change of refrigerants in minichannels. Chłodnictwo 12(2012), 18-21 (in Polish).

[13] Charun H.: Thermal and flow characteristics of the condensation of R404A refrigerant in pipe minichannels. Int. J. Heat and Mass Trans. 55(2012), 2692-2701.

[14] Chen J.Y., Yang K.S., Chang Y.J., Wang C.C.: Two - phase pressure drop of air - water and R410A in small horizontal tubes. Int. J. Multiphase Flow 27(2001), $1293-1299$.

[15] Doerr T.M., Pate M.B.: In-tube condensation heat transfer of refrigerant mixtures. ASHRAE Trans. 100(1994), 547-557.

[16] FRIEDEL L.: Improved friction pressure drop correlation for horizontal and vertical two-phase pipe flow. European Two-Phase Flow Group Meeting, Paper 2, Ispra 1987.

[17] Garimella s., Agarwal A., Killion J.D.: Condensation pressure drop in circular microchannels. Heat Transfer Eng. 26(2005), 1-8.

[18] Jin X., Zhang X.: A new evaluation method for zeotropic refrigerant mixtures based on the variance of the temperature difference between the refrigerant and heat transfer fluid. Energ. Convers. Manage. 52(2011), 243-249.

[19] LiE Y.M., Su F.Q., LAI R.I., LiN T.F.: Experimental study of evaporation pressure drop characteristics of refrigerants $R 134 a$ and $R 407 C$ in horizontal small tubes. Int. J. Heat Mass Trans. 51(2008), 294-301.

[20] Mikielewicz D., Andrzejczyk R., Jakubowska B., Mikielewicz J.: Comparative study of heat transfer and pressure drop during flow boiling and flow condensation in minichannels. Arch. Thermodyn. 35(2014), 3, 17-37.

[21] Mikielewicz D., Andrzejczyk R.: Comparative study of flow condensation in conventional and small diameter tubes. Arch. Thermodyn. 33(2012), 2, 67-83.

[22] Montreal Protocool on substences that deplete the ozone layer. Prepared in Montreal on 16 September 1987 r. Dz.U. [Journal of Laws] from 23 Dec. 1992.

[23] RaJan S.: Comparison of refrigerants R410A and R404A for use in low temperature applications: a computer model study. Ph.D. Thesiss, Mechanical Engineering in the Graduate College of the University of Illinois at Urbana-Champaign, 2011.

[24] Sнан M.M.: A general correlation for heat transfer during film condensation inside pipes. Int. J. Heat . Mass Trans. 22(1979), 547-556.

[25] Son CH.-H., LeE H.-S.: Condensation heat transfer characteristics of R-22, R-134a and $R-410 A$ in small diameter tubes. Heat Mass Transfer 45(2009), 1153-1166.

[26] TANG L.: Empirical study of new refrigerant flow condensation inside horizontal smooth and micro-fin tubes. University of Maryland k, PhD. thesis, College Par 1997. 
[27] The National Archives. Regulation (EC) No 842/2006 of the European Parliament and of the Council of on certain fluorinated greenhouse gases.

[28] Thомe J.R.: Condensation in plain horizontal tubes: Recent advances in modeling of the transfer to pure fluids and mixture. J. Braz. Soc. Mech. Sci. 27(2005), 23-30.

[29] Thome J.R., Hajal J.El., Cavallini A: Condensation in horizontal tubes, part 2: new heat transfer model based on flow regimes. Int. J. Heat Mass Trans. 46(2003), $3365-3387$.

[30] Act on treatment of substances depleting the ozone layer. Dz.U. [Journal of Laws] No 52, item. 537 from 3 March 2001.

[31] Wang Ch.-Сh.: System performance of R-1234yf refrigerant in air-conditioning and heat pump system - An overview of current status. Appl. Therm. Eng. 73(2014), $1-9$.

[32] Zhang M., WebB R.L.: Correlation of two-phase friction for refrigerants in smalldiameter tubes. Exp. Therm. Fluid Sci. 25(2001), 131-139.

[33] Zнао L., GAO P.: Evaluation of zeotropic refrigerants based on nonlinear relationship between temperature and enthalpy. Sci. China: Ser. E. Technol. Sci. 49(2006), 322-331. 